\title{
The Predictive Value of Thrombelastography and Routine Coagulation Tests for Postoperative Blood Loss in Open Heart Surgery
}

\author{
Agnese Ozolina*, Eva Strike*,**, Indulis Vanags** \\ *Pauls Stradins Clinical University Hospital, Department of Anesthesiology and Cardiothoracic Surgery, Riga, Latvia \\ **Riga Stradins University, Department of Anaesthesiology and Reanimatology, Riga, Latvia
}

\section{Summary}

Introduction. Hemorrhage after cardiopulmonary bypass remains a clinical problem.

Aim of the Study. Study was performed to compare efficacy of trombelastography (TEG) and routine coagulation tests in relation for postoperative bleeding after cardiac surgery in CPB.

Materials and methods. Forty-seven adult cardiac surgical patients were enrolled in prospective study at Pauls Stradins Clinical University Hospital in 2010. Blood samples for prothrombin time, international normalized ratio, activated partial thromboplastin time (APTT), fibrinogen level, platelet count were collected before surgery, at admission in intensive care unit (ICU) and 6, 12 hours after operation.

Before induction of general anesthesia blood sample was collected to perform kaolin activated TEG (kTEG) and at admission in ICU kTEG and heparinase- modified kTEG.

Results. Correlation postoperatively was between kTEG reaction time (R) and APTT, as well as heparinase-modified kTEG maximum amplitude (MA) and platelet count. Significant correlation with postoperative bleeding showed heparinase-modified kTEG MA on admission to the ICU.

The highest predictive value preoperatively showed kTEG alpha angle (A), APTT, platelet count and postoperatively kTEG MA, APTT on admission to ICU.

Conclusions. Associated with bleeding are following TEG variables: preoperatively kTEG A, postoperatively kTEG MA and heparinasemodified kTEG MA. APTT and platelet count are also related to postoperative bleeding but to a lesser degree.

Key words: trombelastography, heart surgery, bleeding.

\section{INTRODUCTION}

Hemorrhage after cardiopulmonary bypass (CPB) remains a clinical problem. Many risk factors associated with excessive blood loss have been identified (19), but postoperative bleeding remains poorly explained because of the complexity of the hemostatic process and the technical difficulties imposed by operative procedures. It suggests a need for patient testing to determinate hemostatic disorder after $\mathrm{CPB}$ and to be able differentiate a surgical cause for abnormal bleeding. Thrombelastography (TEG) has been described as a usefull point-of-care monitor during cardiac surgery (12). It measures in vitro viscoelastic properties of the developing clot in whole blood with specific patterns developing in the presence of clotting factor deficiencies, platelet dysfunction/trombocytopenia, hypofibrinogenemia and fibrinolysis (10). The overall coagulation profile can be qualitatively or quantitatively interpreted in terms of the hypo-, normal, or hypercoagulable state of the sample and the degree of lysis. Initiation of clot formation is defined as the reaction time or $\mathrm{r}$-time $(\mathrm{R})$, kinetics of clot development by angle alpha (A) and strenght of the clot by the maximum amplitude (MA).

Various sample preparations can be used wih the TEG analyzer. Native sample type for global evaluation of coagulation takes aproximately 50 minutes to generate data. Activation (Celite, Tissue factor, Kaolin) of the blood sample is essencial to maintain TEG as a pointof-care test, deriving all of the main parameter in 30 minutes.

Heparinase modified thrombelastography will develope despite anticoagulation with heparin during CPB because heparinase neutralizes the anticoagulation properties of heparin.

Routine coagulation tests as activated parcial thromboplastin time (APTT), prothrombin time (PT), international normalized ratio (INR), fibrinogen concentration, platelet count provide no information about the quality of the clot or the dynamics of its formation and they are frequently inadequate for the purpose of monitoring coagulation (10). This was confirmed by several studies. Gravlee and coworkers (7) using 897 cardiac surgical patients concluded that the best multivariate model constructed could explain only $12 \%$ of the observed variation in postoperative blood loss. Similar results were obtained by Gelb et al. (6). They showed that PT, APTT, fibrinogen, factors V, VII, VIII and IX and platelet count have no clinical utility as predictors of clinical bleeding. Regarding to TEG Ereth et al. (5) found that blood samples without the use of activator showed that TEG MA parameter has been more predictive after cardiac surgery then isolated tests of platelet function and routine coagulation tests. The 
kaolin-activated TEG (kTEG) is associated with early coagulopathic bleeding (18) and kTEG parameters had better correlation with bleeding as routine coagulation tests.

The aspect of hemotranfusion management using TEG shows that celite and tissue factor-activated TEG parameters have been successfully used to guide specifice blood product usage (14). As well as heparinase-modified thrombelastography during CPB has been used to reduced haemostatic factor transfusion (16).

\section{AIM OF THE STUDY}

The aim of this study was to compare efficacy of trombelastography and routine coagulation tests in relation for postoperative bleeding after open heart surgery in $\mathrm{CPB}$.

\section{MATERIALS AND METHODS}

After obtaining ethics committee approval of the Paul Stradins Clinical University Hospital and written informed patient consent, 47 adult cardiac surgical patients were enrolled in prospective study between 1 December 2009 and 30 March 2010. Inclusion criteria were age 18 to 70 years, coronary artery bypass grafting or/and valve replacement surgery in CPB, baseline coagulation tests in normal values, anticoagulants or antiplatelet agents were discontinued at least 5 days before surgey. The last dose of low-molekular-weight heparin was administered the evening before surgery. Our exclusion criteria were emergency and redo operations, preoperatively hemostatic disorders or chronic coagulopathy (PT $<50 \%$, INR $>2$, platelet count $<50 \times 10^{9} / \mathrm{l}$ ), renal or/and hepatic failure.

Blood samples testing for PT, INR, APTT, fibrinogen level and platelet count were collected at day before surgery, at admission in intensive care unit (ICU) and 6, 12 hours after operation.

Before induction of general anaesthesia blood sample from radial artery catheter was collected to performe kaolin activated TEG (kTEG) and 1 houre after operation we performed kTEG and heparinase modified kTEG.

The TEG was performed according to the manufacturers instructions using heparinase modified and non heparinase modified samples. Heparinase-containing cups had 2 IU of lypohilized heparinase-1 enzyme from Flavobacterium heparinum, which is sufficient to reverse $6 \mathrm{U} / \mathrm{ml}$ of heparin in whole blood. Following TEG parameters were recorded: reaction time $-\mathrm{R}$ (normal range 4-8 minutes), the alpha angle - A (normal range $47^{0}-78^{\circ}$ ), maximum amplitude - MA (normal range 55-73 mm).

Chest tube drainage (CTD) was recorded at 4 hour and 24 hour postoperatively as milliliters per kilogram. Excessive bleeding was defined as more than $1 \mathrm{ml} / \mathrm{kg} / \mathrm{h}$ in first 4 hours or more than $1000 \mathrm{ml}$ in 24 hours.

Opoid-based anesthesia with fenthanil, midazolam, propafol and cisatracurium was used in all patients. Before the start of CPB heparin was administered in a dose 300 to $400 \mathrm{U} / \mathrm{kg}$ initially and 5,000 to $10,000 \mathrm{U}$ as indicated were given to achieve and maintain a target activated coagulation time (ACT) above 480 seconds before and during CPB. After separation from CPB, protamine was administered in a ratio of $1 \mathrm{mg}: 100 \mathrm{U}$ of heparin, additional protamin was administered until ACT had returned to baseline.

All statistical analysis was performed using Statistical Package for the Social Sciences (SPSS $®$ 16.0). Logistic regression was used to construct the receiver operating characteristic (ROC) curves as there were 8 patients who had a 4-hour CTD more then $1 \mathrm{ml} / \mathrm{kg} / \mathrm{h}$. ROC curves for the outcome of excessive bleeding, were plotted for TEG parameters and routine coagulation tests before and after surgery. Secondary outcomes were the correlation (as Pearson's correlation coefficient) of TEG parameters and routine coagulation tests with CTD. As well as the relationship of TEG parameters and routine coagulation tests was analyzed. We evaluated correlation between reaction time $-\mathrm{R}$ and APTT, angle alpha - A and fibrinogen and maximum amplitude - MA and platelet count.

Continuous variables were described as mean standart deviation and categorical variables as persentages.

\section{RESULTS}

Forty seven adult cardiac surgical patients were examined and 46 completed the study. One patient was excluded after the decision to make off-pump surgery. There were no in-hospital deaths but 3 patients had following postoperative complications: one patient mediastinitis and two cardiac tamponade two and seven days after operation.

There were 28 males and 18 females from the age of 51 to 80 . The mean age of all patients was $67 \pm 7.2$ years Coronary artery bypass grafting underwent 16 (34.8\%), valve replacement surgery $18(39.1 \%)$ and combined surgery $12(26 \%)$ patients. CPB duration was from 50-252 min., aorta occlusion time 33-164 minutes and reperfusion time 11-82 minutes. Cell saver system was used in $76 \%$ cases. Patient demographics are presented in Table 1.

Eight patients (17\%) had excessive bleeding and 1 of them had reexploration for major surgical bleeding. Blood loss statistically differed between patients who had excessive bleeding and who did not 4 hour after operation ( $370 \mathrm{ml}$ vs $155 \mathrm{ml}$ ) and 24 hour after operation (892ml vs $461 \mathrm{ml}$ ).

Preoperatively 44 patients were treated with one or more antiplatelet agents or anticoagulants. Thirty-seven patients received aspirin within $6 \pm 4$ days before surgery, clopidogrel -12 patients ( $8 \pm 2$ days), low molecular weight heparine - 23 patients, the last injection was given 12 hours before surgery. One patient was treated with warfarin within 5 days before operation. There was no statistically significant difference in blood loss between patients with various antiplatelet agents and anticoagulants.

Preoperatively kTEG parameters were within the normal range excepting R time. Average R time was high $17 \pm$ $13 \mathrm{~min}$. and it statistically differed between patients who 
received low molecular weight heparin preoperatively $(21 \pm 15$ vs $12 \pm 8, p<0.003)$. There were no significant differences in kTEG parameters before and after surgery. Baseline routine coagulation tests were within normal ranges, but postoperatively average platelet count was low $149 \pm 48 \times 10^{9} / 1$ and APTT was high $42 \pm 7$ seconds. We found significant correlation postoperatively between the KTEG R and APTT on arrival to the ICU $(\mathrm{r}=0.3, \mathrm{p}=0.03)$, heparinase-modified kTEG MA and platelet count on arrival to the ICU $(r=0.4, p=0.003)$ and platelet count 12 hours postoperatively $(\mathrm{r}=0.3$, $\mathrm{p}=0.02$ ). We did not detect any correlation between any TEG variable and routine coagulation parameter collected before operation.

The strongest correlation with postoperative bleeding showed heparinase-modified kTEG MA on admission to the ICU and bleeding from mediastinal and thoracostomy chest tubes after the first 4 postoperative hours (Fig. 1) and after 24 postoperative hours ( $\mathrm{r}=-0.4$, $p=0.04)$. Additionally heparinase-modified kTEG MA correlated with kTEG A $(r=0.3, p=0.02)$ and kTEG MA $(r=-0.3, p=0.04)$. Others TEG parameters and routine coagulation tests did not show correlation with blood loss.

To describe predictors for bleeding, ROC curves were done. Preoperatively (Fig.2) the highest predictive value showed kTEG A (c-index 0.58) and APTT (c-index 0.68 ), platelet count (c-index 0.5 ) and postoperatively (Fig.3) kTEG MA (c-index 0.64) and APTT on admission to ICU (c-index 0.63).

\section{DISCUSSION}

The TEG has developed as a bedside monitor of the coagulation process over the past 25 years. The device was first popularized by Dr Kang and the group in Pittsburg for monitoring during hepatic transplantation (8).

Others have found TEG very useful for the monitoring of the coagulation during cardiac surgery on CPB as its own induces complex disturbances in the coagulation and fibrinolytic systems $(4,15)$. Many studies have tried to find a predictive value of TEG for abnormal bleeding after CPB. Spiess et al. (15) presented the first study concerning TEG and blood loss after CPB. In a group of 38 patients they found that TEG was a significantly better predictor $(87 \%$ accuracy) of postoperative hemorrhage and need for reoperation than the ACT $(30 \%)$ or routine coagulation tests $(51 \%)$. Essell and coworkers (4) found an abnormal TEG representing an increased risk for bleeding. Also Welsby et al (18) found that kaolin-activated TEG is associated with early coagulopathic bleeding in 32 patients. Cammerer et al. (2) compared TEG and platelet function analysis (PFA) for postoperative bleeding including 255 patients. They found that TEG is a better predictor than PFA.

TEG failed to predict blood loss in other studies. Data from the study by Wang et al. (17) of 101 patients indicated no correlation between amount of CTD and TEG variables. Nutall and coworkers (13) found no correlation between TEG done after CPB and 24-hours blood loss after CPB in 82 patients.
Our results indicate that more closely associated with bleeding are following TEG variables: preoperatively kTEG A, postoperatively non-heparinse-modified kTEG MA and heparinase-modified kTEG MA. Regarding to routine coagulation tests APTT and platelet count are also related to postoperative bleeding but to a lesser degree than TEG variables.

Welsby and coworkers (18) found similar results. The strongest correlation with postoperative blood loss showed heparinize-modified and non-heparinsemodified kTEG MA. Weaker correlation with bleeding showed platelet count, fibrinogen level and PT. In contrast to our data they did not find correlation with blood loss and APTT.

The role of fibrinogen in hemostasis after $\mathrm{CPB}$ is not well examined. There is overall consensus regarding to the dominant role of platelets in hemostasis after CPB. Welsby et al. (18) identified the value of fibrinogen level in relation to bleeding. In our study it did not show correlation with postoperative blood loss. Fibrinogen did not corellate with TEG parameter angle alpha as well. The explanation could be the fact that most of patients received crioprecipitate transfusions after CPB. We found angle alpha in TEG samples collected preoperatively as the best predictor of blood loss. Cammerer and coworkers (2) also found angle alpha as the bests predictor for bleeding and in combination with diphosphate-PFA test the predictive value is enhanced. It confirms our finding of predictive role of kTEG angle alpha and platelet count to the bleeding and role of platelets in hemosthasis after CPB.

Narrani K. (12) described that it is not possible to correlate TEG parameters with conventional coagulation profile as both techniques are different. The conventional coagulation tests measures the various components of the haemosthasis in isolation. TEG measures the various components of haemosthasis as they interract with one another in vivo. Althought many authors have tried to correlate TEG variables with routine coagulation tests. Welsby and coworkers (18) found significant correlation for MA with platelet count, fibrinogen level and PT. Regarding to our results there were correlation between kTEG R and APTT preoperatively and heparinasemodified kTEG MA with platelet count after operation. The present data also challenge current aproaches to interpreting and applying TEG results for hemotransfusion theraphy. $\mathrm{R}$ time has previously been used as a guide for factor replacement with fresh frozen plasma (FFP) transfusions, A-angle alpha for crioprecipitate and MA as a guide for platelet transfusions $(14,16)$. R-time was not correlated with bleeding and PT in our study, suggesting that mainly role plays anticoagulation with heparin affecting $\mathrm{R}-$ time after operations. Althought marked reductions in plasma levels of coagulation proteins are seen during cardiac surgery (6). 


\section{CONCLUSIONS}

More accurately TEG variable is MA as it correlated with postoperative bleeding and platelet count suggesting the dominant role of platelets in hemostasis after CPB. It could be used as a guide for platelet transfusions, but it may be desirable to avoid platelet transfusion as a firstline treatment (1). The MA could be used to identify coagylopathic patients who may benefit from therapies such as Desmopresin administration.

Regarding to routine coagulation tests APTT and platelet count are also related to postoperative bleeding but to a lesser degree.

\section{Conflict of interest: None}

\section{REFERENCES}

1. Blajchman MA, Singal DP. The role of red blood cell antigens, histocompatibility antigens, and blood transfusions on renal allograft survival // Transfus Med Rev, 1989; 3:171-179

2. Cammerer U, Dietrich $\mathrm{W}$, Rampf $\mathrm{T}$, Siegmund LB, Josef AR. The predictive value of modified computerized thrombelastography and platelet function analysis for postoperative blood loss in routine cardiac surgery // Anesth Analg, 2003; 96:51-7

3. Despotis GJ, Levine V, Filos KS. Evaluation of a new point -of-care test that measures PAF-mediated acceleration of coagulation in cardiac surgical patients // Anesthesiology, 1996; 85:1311-23

4. Essell JH, Martin TJ, Salinas J, Thompson JL, Smith VC. Comparision of thromboelastography to bleeding time and standard coagulation tests in patients after cardiopulmonary bypass // J Cardiothorac Vasc Anesth, 1993; 7:410-5

5. Ereth $\mathrm{MH}$, Nuttall AG, Klinworth TJ, MacVeigh I, Santrach PJ, Orszulak TA, Harmsen WS, Oliver WC Jr. Does the Platelet-Activated Clotting Test (HemosTATUs@) Predict Blood loss and Platelet Dysfunction Associated with Cardiopulmonary Bypass // Anesth Analg, 1997; 85:259-64

6. Gelb AB, Roth RI, Levin J, London MJ, Noall RA, Hauck WW, Cloutier M, Verrier E, Mangano DT. Changes in blood coagulation during and following cardiopulmonary bypass:Lack of correlation with clinical bleeding // Am J Clin Pathol, 1996; 106:8799

7. Gravlee GP, Arora S, Lavender SW, Mills SA, Hudspeth AS, Cordell AR, James RL, Brockschmidt JK, Stuart JJ. Predictive value of blood clotting tests in cardiac surgical patient // Ann Thorac Surg, 1994; 58:216-21Kang YG, Martin DJ, Marquez J, Lewis JH, Bontempo FA, Shaw BW Jr, Starzl TE, Winter PM. Intraoperative changes in blood coagulation and thrombelastographic monitoring in liver transplantation // Anesth Analg, 1985; 64:888-96
8. Kettner SC, Panzer OP, Kozek SA, Seibt FA, Stoiser B, Kofler J, Locker GJ, Zimpfer M. Use of abciximab-modified thrombelastography in patients undergoing cardiac surgery // Anesth Analg, 1999; 89:580-4

9. Mallett SV, Cox DJ. Thromboelastography // Br J Anaesth, 1992; 69:307-313

10. Mittermayr M, Velik-Salchner C, Stalzer B. Detection of proatmine and heparin after termination of cardiopulmonary bypass by thrombelastometry (ROTEM®): results of a pilot study // Anesthesia\&Analgesia, 2009; 108(3):743750

11. Narani K.K. Thrombelastography in the perioperative period // Indian J Anaesth, 2005; 49(2):89-95

12. Nutall GA, Oliver WC, Ereth MH, Santrach PJ. Coagulation tests predict bleeding after cardiopulmonary bypass // J Cardiothorac Vasc Anesth, 1997; 11:815-23

13. Shore-Lesseron L, Manspeizer HE, DePerio M. Thromboelastography-guided transfusion algorithm reduces tranfusions in complex cardiac surgery // 1999; 88:312-319

14. Spiess BD, Tuman KJ, McCarthy RJ, DeLaria GA, Schillo R, Ivankovich AD. Thrombelastography as an indicator of post-cardiopulmonary bypass coagulopathies // J Clin Monit, 1987; 3:25-30

15. Royston D, von Kier S. Reduced haemostatic factor transfusion using heparinase-modified thromboealastography during cardiopulmonary bypass // 2001; 86:575-578

16. Wang JS, Lin CY, Hung WT. Thrombelastogram fails to predict postoperative hemorrhage in cardiac patients // Ann Thorac Surg, 1992; 53:435-9

17. Welsby IJ, Jiao K, Ortel TL, Brudney CS, Roche AM, Bennett-Guerrero E, Gan TJ. The Kaolin-activated thrombelastograph predicts bleeding after cardiac surgery // Journal of cardiothoracic and vascular anesthesia, 2006; 20(4):531-535

19. Wolfe R, Bolsin S, Colson M, Stow P. Monitoring the rate of reexploration for excessive bleeding after cardiac surgery in adults // Quality and Safety in Health Care, 2007; 16:192-196

\section{Address:}

Agnese Ozolina

Cardiac Surgery Centre,

Department of Anesthesiology and

Cardiothoracic Surgery

Pauls Stradins Clinical University Hospital

13 Pilsonu street,

Riga, Latvia, LV-1002

E-mail:agnese_krauze@yahoo.com 
Table 1. Patients demographics data

\section{Patient data $(n=46)$}

Gender male 28

$(60.9 \%)$

female 18

Age (yr)

$67 \pm 7.2$

Body mass index $\left(\mathrm{kg} / \mathrm{m}^{2}\right)$

$29 \pm 6.4$

\section{Operation charasteristics}

CABG (\%)

$16(34.8 \%)$

Valve replacement ( \%)

$18(39.1 \%)$

Combined surgery (\%)

$12(26 \%)$

CPB duration (min)

$106 \pm 32$

Aorta occlusion time (min)

$69 \pm 23$

Reperfusion time (min)

$32 \pm 12$

Cell saver (\%) $35(76 \%)$

\begin{tabular}{lcc}
\hline Blood loss $(\mathbf{m l})$ & $>1 \mathrm{ml} / \mathrm{kg} / \mathrm{h}<\mathrm{l} \mathrm{ml} / \mathrm{kg} / \mathrm{h}$ \\
$\mathrm{n}=8$ & $\mathrm{n}=38$ \\
\hline $4 \mathrm{~h}$ after surgery & $370 \pm 61^{*}$ & $155 \pm 57^{*}$ \\
$24 \mathrm{~h}$ after surgery & $892 \pm 179^{*}$ & $461 \pm 167^{*}$ \\
\hline
\end{tabular}

Abbreviations: CABG - coronary artery bypass grafting, $\mathrm{CPB}$ - cardiopulmonary bypass

${ }^{*} \mathrm{p}<0,05$

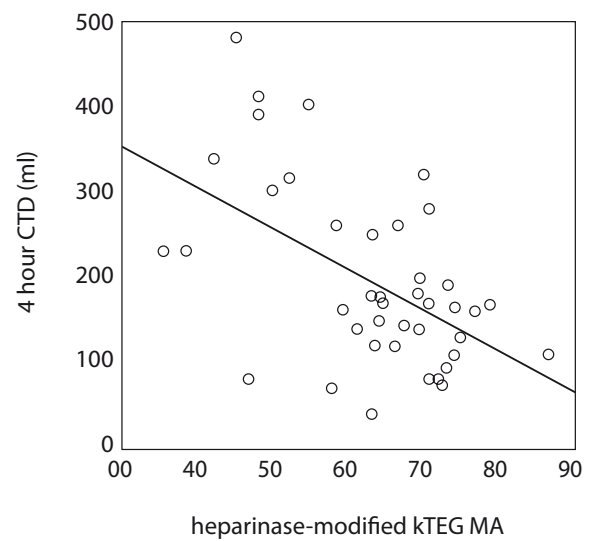

Fig. 1. Negative linear correlation of the heparinasemodified KTEG MA on admission to the ICU with bleeding from the mediastinal and thoracostomy tubes during the first 4 postoperative hours ( $r=-$ $0.5, \mathrm{p}<0.001$ )

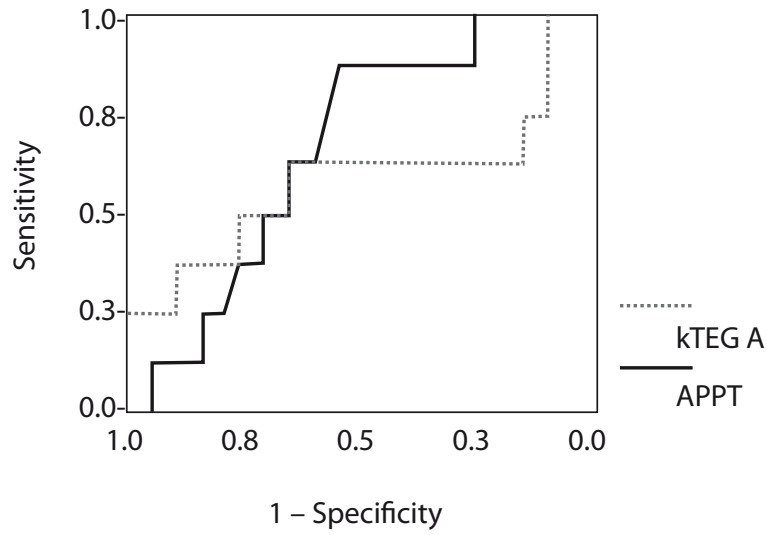

Fig. 2. ROC curves describing the relationship between the kTEG $A$ - angle alpha parameter (c-index, 0.58) and APTT - activated parcial thromboplastin time (c-index, 0.68) before operation and excessive postoperative bleeding

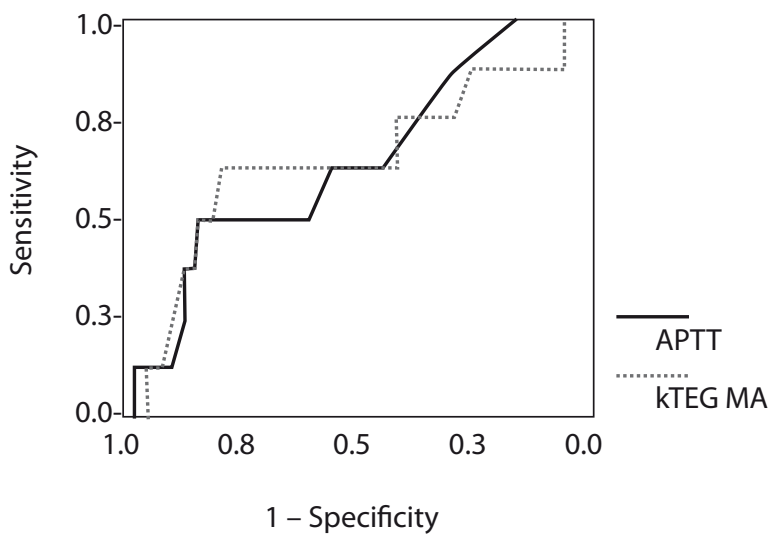

Fig. 3. ROC curves describing the relationship between the kTEG MA - maximum amplitude parameter (c-index, 0.64) and APTT - activated parcial thromboplastin time (c-index, 0.63) on arrival to the ICU and excessive postoperative bleeding 